REVIEW

\title{
When is the right time? Complex issues around withdrawing life-sustaining treatment in children
}

\author{
J Ambler, MB ChB, MRCGP (UK), Dip Pall Med (Cardiff), DCH (SA) \\ Department of Paediatrics, University of KwaZulu-Natal and Umduduzi Hospice Care for Children, Durban, South Africa
}

Corresponding author: J Ambler (julia@umduduzi.co.za)

When should one withdraw treatment in children? The challenge is to recognise when a decision needs to be made. Parents may be in denial, and deciding which questions to ask may be difficult. Ethically, the guiding principle should be the child's best interests. May the parents or primary caregiver decide what the child's best interests are? Legislation in South Africa prevents a parent or caregiver from refusing treatment that medical professionals deem to be in the child's best interests. This article discusses the ethical and legal aspects around the decision to palliate in children.

S Afr Med J 2014;104(7):507-509. DOI:10.7196/SAMJ.8427

口誓和回

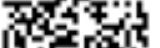

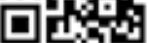

Healthcare practitioners are often faced with difficult decisions, but the real challenge is to recognise when a decision needs to be made. In a busy general practice, managing a chronically ill child you are not attending to daily, the most straightforward approach may be to continue with a treatment plan for the child and family without reflecting on the course of events over time. The parents may be in denial about the condition of the child and it may be particularly difficult to step back and identify which questions need to be asked.

\section{Case study}

Let me introduce Sara and Jade. Sara is a 10-year-old girl with quadrispastic cerebral palsy. Her mother, Jade, has been bringing her to you since they moved to the area many years ago. Sara is profoundly impaired - physically and mentally. Both her sisters are much older and have left home already. Sara is the centre of Jade's life. Sara's father and Jade are divorced. He could not cope with Jade's 'obsession' with Sara.

Sara does not make eye contact and is unable to communicate. Although she barely moves and has severe spasticity, she has generally been well - until recently. During the past 9 months Sara has refused to eat, vomited frequently, and has been admitted to the local hospital five times for pneumonia. She does not sleep well and cries much of the time. She has undergone numerous invasive investigations, but her condition is not improving. Gastrostomy feeding has been discussed, but the surgical team did not feel it was necessary as neither parent was in favour of Sara undergoing surgery.

Jade is not coping and feels that Sara is misbehaving. Sara's father doesn't see her often as he travels for work and finds it easier not to interfere with Jade's management of Sara.

Your heart sinks as you see they have another appointment. When Jade and Sara enter, you immediately realise that Sara has pneumonia. She is short of breath and moaning. Her muscle spasms seem worse. Jade is exhausted. Sara has lost more weight and refuses her normal feeds.

You call their paediatrician and again Sara is admitted to the ward, with referrals to the physiotherapist and dietician. As Jade leaves your rooms she asks, 'What are we going to do next?'.

Jade's question is very important. In such a case it is very easy to practise reactive medicine, responding to each acute episode individually without asking difficult questions. Perhaps we need to ask, 'What should we do next?'.

\section{How do we approach a case such as this one?}

There are three key considerations when regarding difficult ethical decisions in caring for children:

- What is the ethical issue in this case?

- Who should make this decision?

- How is the decision made? 


\section{What is the ethical issue in this case?}

Before you can make decisions, you must define the questions. Sara is a chronically ill, neurologically impaired child whose clinical condition is deteriorating. She is uncomfortable and does not tolerate food. The burden of caring for her is enormous and taking its toll on her mother.

We need to consider whether managing Sara in this reactive manner is in her best interests. What is the benefit versus harm of recurrent hospitalisation? Do we have alternative options with regard to her management? What should we be doing about feeding her?

\section{Who should make this decision?}

Very often, healthcare decisions are left to the parents or primary caregiver as it is assumed that they will understand the child's best interests. Parents and healthcare workers should be working as a team, ensuring open and honest communication at all times. The healthcare professional must identify the key decision makers in a family. However, it is important to note that legislation in South Africa prevents a parent or caregiver refusing treatment that medical professionals deem to be in the child's best interests. ${ }^{[1]}$ Dealing with children is complex - one must be able to manage the parents and the child.

\section{What about the child?}

In our case study, the child lacks the capacity to be autonomous as she is severely mentally impaired. There is, however, increasing evidence that children should be involved in their own healthcare decisions. ${ }^{[2-5]}$ The Children's Act 38 of 2005 (amended by Act 41 of 2007), promulgated in 2010, emphasises child participation. 'Every child that is of such an age, maturity and stage of development as to be able to participate in any matter concerning that child has the right to participate in an appropriate way and views expressed by the child must be given due consideration. ${ }^{\text {[6] }}$

The act also states, 'Patients, including children, have a right to have sufficient information about their health to enable them to make an informed decision about treatment. The information must be "relevant and must be in a format accessible to children, giving due consideration to the needs of disabled children". ${ }^{[6]}$ This is echoed in the Health Professions Council of South Africa's Guidelines for the Withholding and Withdrawing of Treatment. ${ }^{[7]}$

Deciding whether a child has the capacity to make decisions may be difficult, but should take into account the child's ability to reason, their understanding (which may be based on previous experience), their willingness to consent and the seriousness of the situation. ${ }^{[4]}$ There are no hard-and-fast rules, as children vary greatly depending on age, rate of development, social circumstances and educational level. Each situation needs to be assessed individually. In South Africa, children are very seldom involved in their healthcare decisions and a shift in attitude needs to occur if we are to comply with the Children's Act. ${ }^{[6]}$
Many healthcare professionals have been involved in Sara's care over a long period of time. It is imperative that everyone be included in the discussions and decision making to prevent conflicts arising in the team. Both her parents, and possibly even the adult siblings who are also affected by the decisions, should be included in the discussion.

\section{How do decisions get made? Key ethical principles \\ - Autonomy \\ - Beneficence \\ - Non-maleficence \\ - Justice}

When considering children, the standard of 'best interests' applies. Best interests usually refer to the 'highest net benefit among the available options that apply to any situation in which a decision has to be made regarding the health of the child. ${ }^{[8]}$

The Children's Act ${ }^{[6]}$ states that 'The best interests of a child are of paramount importance in every matter concerning the child'. This has to take into account every aspect of the child's life, including age, maturity, family dynamics, illness, educational needs and disability.

It is not always easy to know what is in the child's best interests, but Kopelman ${ }^{[9]}$ argues that taking a child's best interests into account does not require what is ideal, but what is reasonable. In deciding what is in the child's best interests, most healthcare workers try to calculate the consequences of the various treatment options available and choose the one likely to do the least harm (non-maleficence) and the most good (beneficence) to the child.

Although the best interests of the child must carry the most weight, 'any decision made in respect of the child must carefully consider the interests of all potentially affected persons, most usually other family members, old or young, who will live with the child or are dependent upon the immediate family in other ways. ${ }^{[10]}$

To apply the standard of best interests we need the following:

- a good understanding of the ethical principles

- all the available information relevant to the case

- an understanding of the child's quality of life

- a clear idea of treatment goals

- the ability to examine our own motives.

\section{Quality of life}

Quality of life is difficult to define but has been described as an individual's satisfaction or happiness with life in domains he or she considers important. ${ }^{[11]}$ It is a subjective measure, but in the case of the disabled child it is important to consider the primary caregiver's opinion on the quality of the child's life.

The Royal College of Paediatrics and Child Health (RCPCH), UK, has defined the following five situations associated with poor 
or absent quality of life where life-sustaining therapies may be withdrawn or withheld ethically and legally: ${ }^{[12]}$

- brainstem death

- persistent vegetative state

- 'no chance' situation - further treatment is futile

- 'unbearable' situation - suffering is intolerable and disease is progressive and irreversible (burden of treatment exceeds benefit)

- 'no purpose' situation - prolonging life is possible, but at the cost of severe physical or mental impairment.

We could argue that Sara's quality of life has deteriorated significantly and that she fits into the 'no purpose' situation. By inserting a gastrostomy tube and allowing recurrent hospitalisation we can, in all likelihood, prolong Sara's life but at what cost to her and her family? This decision would have to take into account her fitness for an operation and the potential negative side-effects of surgery and gastrostomy feeding. This needs to be discussed with the family and team in a sensitive manner.

Furthermore, it is clear that Sara is in pain. We have an ethical responsibility to identify the sources and manage them accordingly to ensure comfort and thereby improve her quality of life.

\section{Goals of treatment}

Understanding what we are hoping to achieve can guide our decisionmaking process. On the one hand, the goal may be to cure the child, in which case forcing the child to endure unpleasant treatments or investigations is reasonable. On the other hand, when cure is not possible, as in Sara's case, the goal may be to ensure the child's comfort and maximise her quality of life. In this situation one would certainly limit hospitalisation and exposure to painful procedures. Defining the goals of treatment must be done together with the parents, considering the impact of the treatment on the entire family.

\section{Motives}

Examining one's own motives is exceptionally important, particularly when one is close to a family and child. Knowing that you did everything possible for the child does not mean it was the right thing to do, especially if 'everything' had a negative impact on the child's quality of life. If you have been involved with a family and a child over many years, this can be very difficult.

\section{Requirements for good ethical decision making}

- Good understanding of basic ethical principles

- Good understanding of the Children's Act and how it applies to your practice

- All the medical facts

- Teamwork

- Excellent communication skills

- Common sense

- Compassion

\section{Conclusion}

Making ethical decisions is never easy. As healthcare practitioners we first need to be able to identify when an ethical decision needs to be made and then have a framework of ethical principles to guide us in making the decision. Decisions need to be made in the child's best interests, taking into account all the relevant facts, impact on the family and goal of care.

\section{References}

1. Jamieson L, Lake L. Children's Act Guide for Health Professionals. 5th ed. Cape Town: Children’ Institute, University of Cape Town, 2013. http://www.ci.org.za/depts/ci/pubs/pdf/resources/guides/2013/ (accessed 1 March 2014).

2. United Nations Childrens Fund (UNICEF). Convention on the Rights of the Child. http://www.unicef org (accessed 24 March 2014)

3. King NM, Cross AW. Children as decision makers: A guideline for pediatricians. J Pediat 1989;115(1):10-16. [http://dx.doi.org/10.1016/S0022-3476(89)80321-X]

Aspinall C. Children and parents and medical decisions. Hastings Center Report 2006;36(6):3. [http:// dx.doi.org/10.1353/hcr.2006.0088

5. Lansdown G. Implementing children's rights and health. Arch Dis Child 2000;83:286-288.

6. Children's Institute. Consolidated Children's Act. http://www.ci.org.za/depts/ci/pubs/pdf/lawreform/ billsacts/consolidated_childrens_act_lapril2010.pdf (accessed 3 March 2014).

. Health Professions Council of South Africa. Guidelines for the Withholding and Withdrawing of Health Professions Council of South Africa. Guidelines for the Withholding and Withdrawing of Treatment, May 2007, Booklet 13, Section 14.4. http://www.hpcsa.co.za (accessed 11 November 2013). 8. Beauchan IL, Cimedical Ethics. 5th ed. Oxford: Oxford University Press, 200 Kopelman LM. The best-interests standard as threshold, ideal, and standard of reasonableness. J Me Philos 1997;22:271-289. [http://dx.doi.org/10.1093/jmp/22.3.271]

10. Nuffield Council on Bioethics. Critical care decisions in fetal and neonatal medicine: Ethical issues. November 2006. http://www.nuffieldbioethics.org/sites/default/files/CCD\%20web\%20version $\% 20$ 22\%20June\%2007\%20 (accessed 6 March 2014).

11. Oleson M. Subjectively perceived quality of life. Image 1990;22:187-190.

12. Royal College of Paediatrics and Child Health (RCPCH). Withholding or Withdrawing Life Sustaining Treatment in Children: A Framework for Practice. 2nd ed. London: RCPCH, 2004. http://www.gmcuk.org/Withholding pdf 40818793 pdf (accessed 6 March 2014). 